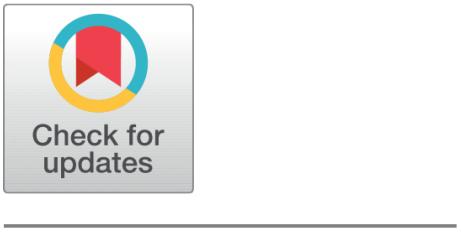

open ACCESS

Received: 18.05.2021

Accepted: 19.07.2021

Published: 03.11 .2021

Citation: Alashhab MS, Mlybari EA (2021) Developing a multi-item, multi-product, and multi-period supply chain planning optimization model. Indian Journal of Science and Technology 14(37): 2850-2859. https://doi.org/

10.17485/IJST/v14i37.867

* Corresponding author.

msashhab@uqu.edu.sa

Funding: None

Competing Interests: None

Copyright: (c) 2021 Alashhab \& Mlybari. This is an open access article distributed under the terms of the Creative Commons Attribution License, which permits unrestricted use, distribution, and reproduction in any medium, provided the original author and source are credited.

Published By Indian Society for Education and Environment (iSee)

ISSN

Print: 0974-6846

Electronic: 0974-5645

\section{Developing a multi-item, multi-product, and multi-period supply chain planning optimization model}

\author{
Mohamed Sayed Alashhab ${ }^{1,2 *}$, Ehab A Mlybari ${ }^{1}$ \\ 1 College of Engineering and Islamic architecture, Umm Al-Qura University, Makkah, Saudi \\ Arabia \\ 2 Faculty of Engineering, Ain-Shams University, Cairo, Egypt
}

\section{Abstract}

Objectives: To develop a multi-item, multi-product, and multi-period mathematical model that optimizes supply, production, distribution, and inventory planning for a supply chain network. Methods: Mixed Integer Linear Programming has been used to formulate the proposed model, while Excel and Evolver solvers have been used to solve problems regarding supply chain network (consisting of two suppliers and two retailers) for profit maximization. Findings: The analysis showed that the developed model has the ability to efficiently and effectively solve real-life problems of the multi-item, multi-product, and multiperiod supply chain. Novelty: The model considered multi-item, multi-product, and multi-period. In addition, it considers initial, final, and intermittent inventory in multi-periods. The model is solved using both Excel and Evolver solvers. The model assists organizations involved in the supply chain to design and plan their network efficiently.

Keywords: Supply chain; multi-item; multi-products; multi-periods; MILP; Excel; Evolver Solver

\section{Introduction}

Research on Supply chain management (SCM) has gained remarkable attention among academics and practitioners ${ }^{(1)}$. SCM is responsible for coordinating different business functions through a supply chain and within a company to optimize the supply chain and individual companies' productivity ${ }^{(2)}$. The supply chain is a network that connects material sources, manufacturing facilities with suppliers and retailers ${ }^{(3)}$.

To reduce the environmental and economic impacts of supply chains in ${ }^{(4)}$, a singleitem comprehensive green supply chain planning optimization model is created. $\operatorname{In}^{(5)}$, a multi-objective, single-item, single-period optimization model in the strategic supply network planning process that includes the environmental investment decision is suggested. In ${ }^{(6)}$, a multi-period multi-echelon forward-reverse logistics network design under risk for only single item products is proposed. $\operatorname{In}^{(7)}$, a mathematical model for a single item, single product, multi-period, multi-echelon supply network considering perishability has been developed. In ${ }^{(8)}$, only one product has been considered in a formulated MINLP model for a two-echelon vehicle routing problem. A single item 
and a single objective are considered in ${ }^{(9)}$ since a mathematical model has been proposed to minimize the silo establishment costs. In ${ }^{(10)}$, a four objective MILP model considering only a single item was developed. In ${ }^{(11)}$, the cost and benefit optimization of a multi-product single-item SCN is studied. No prior research has designed a model for multi-item, and multi-product supply chain design and planning. So, it has been decided that a multi-item, multi-product, and multi-period mathematical model be developed to optimize supply, production, distribution, and inventory planning for a supply chain that consists of two suppliers and two retailers to maximize the profit. The proposed model has been formulated using MILP and solved using Evolver solver.

This work is an extension of the work done in ${ }^{(4,12)}$. It entails the supply chain network's configuration and influence of performance considering the stated objectives ${ }^{(13)}$. So, it was decided that the profit be maximized directly in this work.

The proposed supply chain consists of three stages of potential suppliers, and retailers in a factory as shown in Figure 1.

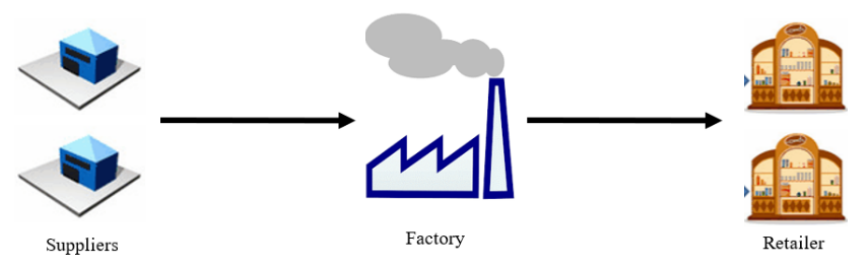

Fig 1. Supply chain diagram

The following assumptions were considered:

- Each product is composed of multi-items.

- The model aims to maximize profit.

- All products may have Initial/final inventory.

- All facilities have limited capacity for each period.

- The customers' demands are deterministic and known.

\section{Model formulation}

\section{Sets:}

P: Set of products,

I: Set of items,

S: Set of potential suppliers,

C: Set of potential retailers,

$\mathrm{T}$ : Set of periods,

\section{Parameters:}

FFCt: facility's fixed cost at period $\mathrm{t}$

$\mathrm{DEM}_{c p t}$ : demand of retailer $\mathrm{c}$ from product $\mathrm{p}$ in period $\mathrm{t}$ (unit/period)

REQip: Required amount of item i for product $\mathrm{p}$ (unit)

IIf $_{p}$ : the initial inventory of product $\mathrm{p}$ (unit)

FIf $_{p}$ : the final inventory of product $\mathrm{p}$ (unit)

$\mathrm{P}_{p c t}$ : the unit price of product $\mathrm{p}$ at retailer $\mathrm{c}$ in period $\mathrm{t}(\$)$

$\mathrm{W}_{p}$ : the weight of product $\mathrm{p}(\mathrm{kg})$

$\mathrm{MH}_{p}$ : manufacturing hours for product $\mathrm{p}$ (hour)

$\mathrm{D}_{s f}$ : the linear distance between supplier s and the facility $(\mathrm{km})$

$\mathrm{D}_{f c}$ : the linear distance between the facility and retailer $\mathrm{c}(\mathrm{km})$

$\mathrm{CAP}_{\text {sit }}$ : the capacity of supplier $\mathrm{s}$ for item $\mathrm{i}$ in period $\mathrm{t}(\mathrm{kg})$

$\mathrm{CAPHf}_{t}$ : manufacturing capacity of the facility in period $\mathrm{t}$ (hour)

$\mathrm{CAPMf}_{t}$ : raw material storing capacity of the facility in period $\mathrm{t}(\mathrm{kg})$

$\mathrm{CAPFSf}_{t}$ : the finished good storing capacity of the facility in period $\mathrm{t}(\mathrm{kg})$

MATCsit: material cost per unit of item i supplied by supplier $\mathrm{s}$ in period $\mathrm{t}(\$ / \mathrm{kg})$ 
$\mathrm{MC}_{f t}$ : manufacturing cost per hour for the facility in period $\mathrm{t}(\$ /$ hour $)$

$\mathrm{MH}_{p}$ : manufacturing hours for product $\mathrm{p}$ (hour)

NUCCf: non-utilized manufacturing capacity cost per hour of the facility (\$/hour)

$\mathrm{SCPU}_{p}$ : back-ordering cost per unit per period (\$/unit/period)

HC: holding cost per unit weight per period at the facility store $(\$ / \mathrm{kg} /$ period $)$

$\mathrm{B}_{s i}$ : the batch size of item $\mathrm{i}$ transported from supplier s to the factory(unit)

$\mathrm{Bf}_{p}$ : batch size transported from the facility for product $\mathrm{p}$ to retailer (unit)

$\mathrm{TC}_{m t}$ : transportation cost for the transportation mode per kilometer in period $\mathrm{t}(\$ / \mathrm{km})$

\section{Decision Variables:}

$$
\mathrm{L}_{\mathrm{s}}=\left\{\begin{array}{l}
1, \text { if supplier } s \text { is contracted } \\
0, \text { if otherwise }
\end{array}\right.
$$

$\mathrm{QSF}_{\text {sit }}$ : number of batches of item i transported from suppliers to the facility in period $\mathrm{t}$

$\mathrm{QFC}_{c p t}$ : number of batches of product $\mathrm{p}$ transported from the facility to retailer $\mathrm{c}$ in period $\mathrm{t}$

$\mathrm{IFF}_{p t}$ : number of batches transported from the facility to its store for product $\mathrm{p}$ in period $\mathrm{t}$

$\mathrm{IFC}_{c p t}$ : number of batches transported from store of the facility to retailer $\mathrm{c}$ for product $\mathrm{p}$ in period $\mathrm{t}$

$\mathrm{Rf}_{p t}$ : facility store a residual inventory of product $\mathrm{p}$ in period $\mathrm{t}$

The profit is calculated by subtracting the total cost from the total revenue. The total revenue is calculated using Equation 1.

$$
\text { Total revenue }=\sum_{c \in C} \sum_{p \in P} \sum_{t \in T}\left(Q_{f c p t}+I_{f c p t}\right) B f_{p} P_{p c t}
$$

The total cost is the summation of the following costs.

- Fixed Cost

$$
\text { Fixed cost }=\sum_{t \in T} F F C_{t}
$$

- Material costs

After subtracting the cost of the final inventory material, the material costs include both summaries of the material supplied to the factory and the cost of the initial inventory.

$$
\sum_{s \in S} \sum_{i \in I} \sum_{t \in T}\left(Q_{s f i t} B_{s i} \text { MatCost }_{s i t}\right)+\sum_{i \in I} \sum_{p \in P}\left(I I F_{p} R Q_{i p} \text { MatCost }_{s i 1}\right)-\sum_{i \in I} \sum_{p \in P}\left(F^{\prime} F_{p} R E Q_{i p} \text { MatCost }_{s i T}\right)
$$

- Manufacturing costs

The manufacturing costs include both the amounts of the factory's manufacturing costs distributed to all suppliers and the manufacturing costs of the initial inventory after deducting the manufacturing costs of the final inventory.

$\sum_{c \in C} \sum_{p \in P} \sum_{t \in T}\left(Q_{f c p t} B f_{p} M H_{p} M C_{t}\right)+\sum_{p \in P} \sum_{t \in T}\left(I f f_{p t} B f_{p} M H_{p} M C_{t}\right)+\sum_{p \in P}\left(I I F_{p} M H_{p} M C_{1}\right)-\sum_{p \in P}\left(F I F_{p} M H_{p} M C_{T}\right)$

- Non-Utilized capacity cost (for the facility)

The cost of the facility's non-utilized capacity is calculated by multiplying the depreciation per hour of machines during non-utilized time by the non-utilized capacity hours.

$$
\sum_{t \in T}\left(C A P H F_{t}-\sum_{c \in C} \sum_{p \in P} \sum_{t \in T}\left(Q_{f c p t} B f_{p} M H_{p}\right)-\sum_{p \in P} \sum_{t \in T}\left(I f f_{p t} B f_{p} M H_{p}\right)\right) N U C C_{f}
$$

- Back-ordering cost (for retailers)

The back-ordering cost is determined by multiplying the shortage quantities and commodity overall times for all retailers by the shortage cost per unit per day. 


$$
\sum_{p \in P}\left(\sum_{c \in C}\left(\sum_{t \in T}\left(\sum_{1}^{t} D E M_{c p t}-\sum_{1}^{t}\left(Q_{f c p t}+I_{f c p t}\right) B f_{p}\right)\right)\right) S C P U_{p}
$$

- Transportation costs

For all shipments in all transportation types at all times for transporting both raw materials from manufacturers and finished products to retailers, transportation costs are determined by multiplying the distance traveled by the transportation cost per unit of distance.

$$
\sum_{s \in S}\left(\sum_{t \in T}\left(N_{s f t} T C_{t} D_{s f}\right)\right)+\sum_{c \in C}\left(\sum_{t \in T}\left(N_{f c t} T C_{t} D_{f c}\right)\right)
$$

- Inventory holding costs

Except for the previous year, inventory costs are determined using the weights of the remaining commodity inventory at the end of each year in addition to the retention of the initial inventory.

$$
\sum_{p \in P}\left(\sum_{1}^{T-1}\left(R f_{p t} B f_{p} W_{p} H C\right)\right)+\sum_{p \in P}\left(I I F_{p} B f_{p} W_{p} H C\right)
$$

\subsection{Constraints}

To ensure flow balance and capacity limits, this model considered two types of constraints.

\subsubsection{Balancing Constraints}

$$
\begin{gathered}
\sum_{s \in S}\left(Q_{s f i t} B_{s}\right)=\sum_{c \in C} \sum_{p \in P}\left(Q_{f c p t} B f_{p} R E Q_{i p}\right)+\sum_{p \in P}\left(I f f_{p t} B f_{p} R E Q_{i p}\right), \forall i \in I, \forall t \in T \\
I f f_{p 1} B f_{p}+I I f_{p 1}=R F_{p 1} B f_{p}+\sum_{c \in C}\left(I_{f c p 1} B f_{p}\right), \forall p \in P \\
I f f_{p t} B f_{p}+I I f_{p(t-1)}=R F_{p t} B f_{p}+\sum_{c \in C}\left(I_{f c p t} B f_{p}\right) \quad \forall 2 \rightarrow T-1, \forall p \in P \\
R F_{p T} B f_{p}=F I f_{p}, \forall p \in P \\
\sum_{1}^{t}\left(Q_{f c p t}+I_{f c p t}\right) B f_{p}=\sum_{1}^{t} D E M_{c p t}, \forall t \in T, \forall c \in C, \forall p \in P
\end{gathered}
$$

Constraint (9-13) ensures that materials and goods flow in a balanced manner.

\subsubsection{Capacity Constraints:}

$$
\begin{gathered}
\left(Q_{s f t} B_{s}\right) \leq C A P_{s i t} L_{s}, \forall s \in S, \forall i \in I, \forall t \in T \\
\sum_{i \in I}\left(Q_{s f i t} B_{s}\right) \leq C A P M f_{t}, \forall t \in T \\
\sum_{c \in C} \sum_{p \in P}\left(Q_{f c p t} B f_{p} M H_{p}\right)+\sum_{p \in P}\left(I f f_{p t} B f_{p} M H_{p}\right) \leq C A P H f_{t} L_{f}, \forall t \in T
\end{gathered}
$$




$$
\sum R F_{p t} B f_{p} W_{p} \leq C A P F S_{t} L_{f}, \forall t \in T
$$

Constraint (14-16) ensures that all facilities work within their limited capacities.

Constraint (17) guarantees that the facility store's remaining inventory does not surpass its storing capacity at any given time.

The Overall Service Level (OSL) is determined using Equation 18 as the ratio between the total weights of products sent to all retailers during the planning horizon and the weight of products requested during the same planning horizon.

$$
O C S L=\sum_{c \in C} \sum_{p \in P} \sum_{t \in T}\left(\left(Q_{f c p t}+I_{f c p t}\right) B f_{p} W_{p}\right) / \sum_{c \in C} \sum_{p \in P} \sum_{t \in T}\left(D E M_{c p t} W_{p}\right)
$$

\section{Model verification}

The efficacy of the model has been verified through the following comprehensive example.

\subsection{Verification example inputs}

To verify the model, the following random example is solved, and the results are analyzed. The assumed demands are shown in Table 1, while Table 2 represents other parameters.

Table 1. Demand of the retailers of products over 6 periods

\begin{tabular}{lllllllll}
\hline Period & & 1 & 2 & 3 & 4 & 5 & 6 \\
\hline \multirow{2}{*}{ Retailer 1 } & Product 1 & 2,200 & 2,700 & 3,200 & 3,700 & 4,200 & 4,700 \\
& Product 2 & 500 & 650 & 800 & 950 & 1,100 & 1,250 \\
\hline \multirow{2}{*}{ Retailer 2 } & Product 1 & 2,100 & 2,350 & 2,600 & 2,850 & 3,100 & 3,350 \\
& Product 2 & 600 & 700 & 800 & 900 & 1,000 & 1,100 \\
\hline
\end{tabular}

\begin{tabular}{|c|c|c|c|c|c|c|c|}
\hline No. & Input parameter & Value & Unit & No. & Input parameter & Value & Unit \\
\hline 1 & $\mathrm{~S}$ and $\mathrm{C}$ & 2 & - & 14 & MCft & 2 & $\$ / \mathrm{hr}$ \\
\hline 2 & $\mathrm{P}$ & 2 & - & 15 & MHp & 1,2 & hrs \\
\hline 3 & IIfp & 10,10 & Unit & 16 & $\mathrm{MCft}$ & 10 & $\$ / h r$ \\
\hline 4 & FIfp & 20,10 & Unit & 17 & NUCCf & 1 & $\$ / \mathrm{hr}$ \\
\hline 5 & Ppct & 110,220 & \$/Unit & 18 & SCPUp & 5 & $\$ /$ period \\
\hline 6 & $\mathrm{~W} 1,2$ & 6,12 & $\mathrm{Kg}$ & 19 & $\mathrm{HC}$ & 0.75 & $\$ / \mathrm{kg}$. period \\
\hline 7 & MH1,2 & 1,2 & Hrs & 20 & Bsi & 10,5 & Unit \\
\hline 8 & CAPsit & 18,000 & $\mathrm{Kg}$ & 21 & Bfp & 1,1 & Unit \\
\hline 9 & CAPHft & 10,000 & Hrs & 22 & TCt & 0.05 & $\$$ \\
\hline 10 & CAPMft & 50,000 & $\mathrm{Kg}$ & 23 & FC & 50,000 & $\$$ \\
\hline 11 & CAPFSft & 10,000 & $\mathrm{Kg}$ & 24 & $\mathrm{Bf}$ & 1 & unit \\
\hline 12 & MATCit & $0.9,1,2.7,2.8$ & $\$ / \mathrm{kg}$ & 25 & Dsf & $55.8,40.4$ & $\mathrm{Km}$ \\
\hline 13 & REQip & $4,8,2,1$ & Kg./unit & 26 & $\mathrm{Dfc}$ & $14.8,22.4$ & $\mathrm{Km}$ \\
\hline
\end{tabular}

Table 2. Listof input parameters and their respective values

\subsection{Verification example Results and discussion}

The model is solved using Evolver software on an Intel ${ }^{\circledR}$ Core $^{\mathrm{TM}} \mathrm{i7}-7700 \mathrm{CPU} @ 3.60 \mathrm{GHz} 4$ Core(s) 8 logical processors $(8 \mathrm{~GB}$ of RAM).

Figure 2 shows that the demands of the first product have been satisfied, while the demand of the second product has not been fully satisfied as shown in Figure 3, where the unit contribution of the first product is larger than that of the second product.

For more discussion, the demand of each retailer from each product has been studied individually. From Figures 4 and 6 , it can be observed that the demands for the first product of both retailers have been satisfied, while the demands of the second product of both retailers have not been fully satisfied as shown in Figures 5 and 7, respectively. It is also clear to observe that the shortage of the first retailer is less than that of the second retailer because of its closeness to the factory which minimizes the transportation cost contrary to the second retailer's demands which are partially satisfied as shown in Figures 5 and 7. 


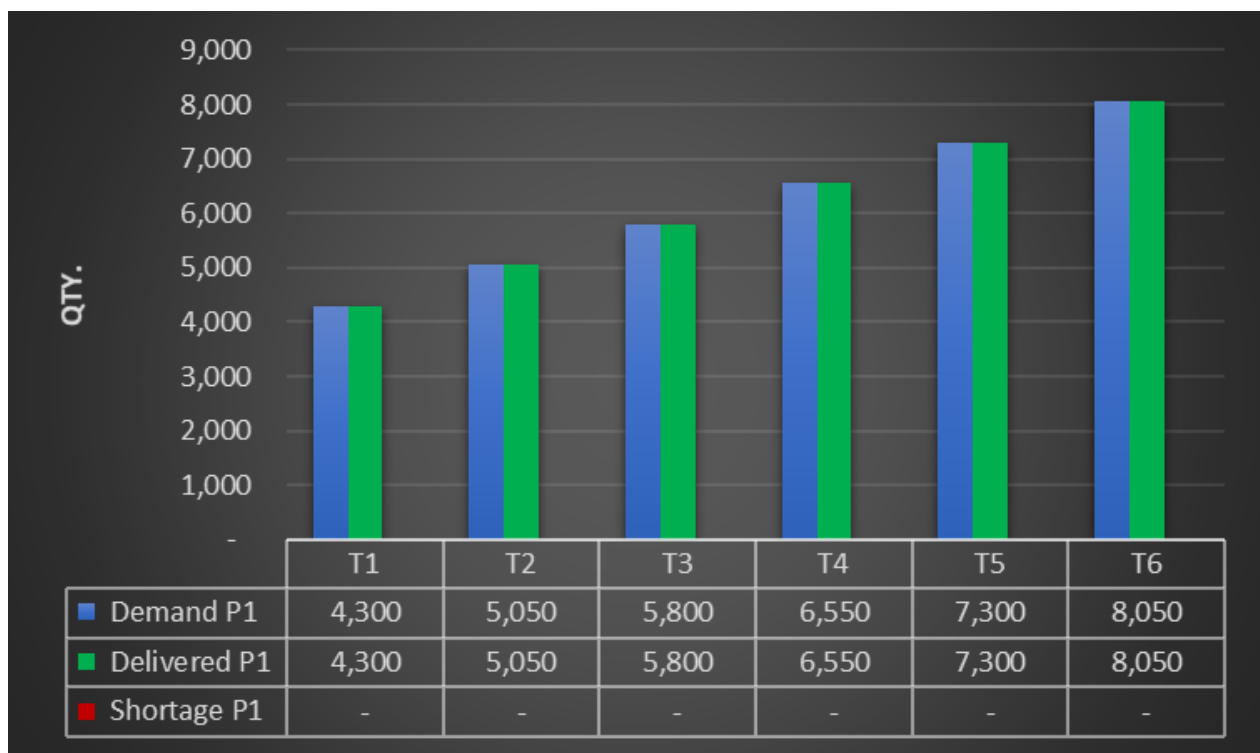

Fig 2. The relation between the demand and delivered quantities of the first product

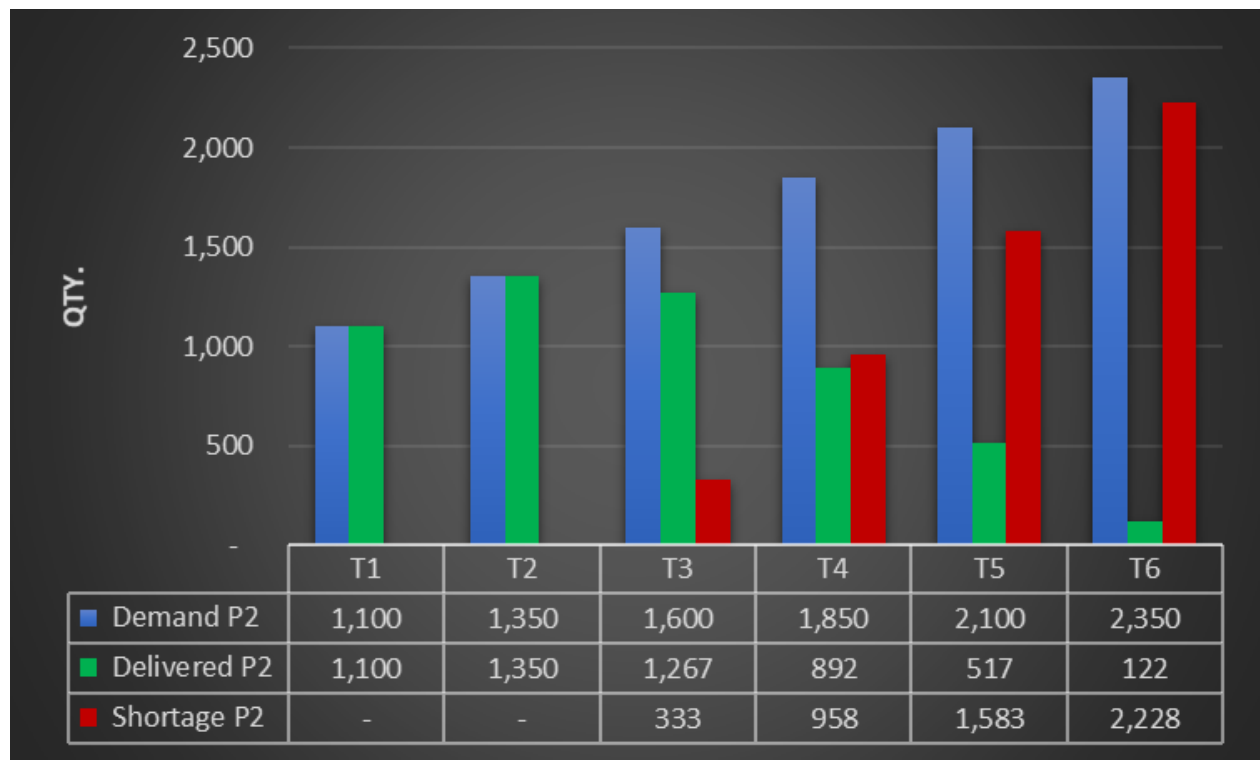

Fig 3. The relation between the demand and delivered quantities of the second product

Balancing of the supplied material and the received products during all periods have been presented in Table 3 verifies the developed model.

Table 3 represents the relationships between facilities' capacities, demand, received quantities, and the residual inventory for all periods.

\section{Computational Results and analysis}

In this section, the effect parameter change has on system behavior has been studied. The following parameters are shown in Table 4 has been assumed to simplify the discussion.

The effect of demand on the total revenue, cost, profit, and OSL have been studied by assuming equal demands for all products and customers in all periods. The results of this study have been presented in Figure 8 from which it was observed that the 


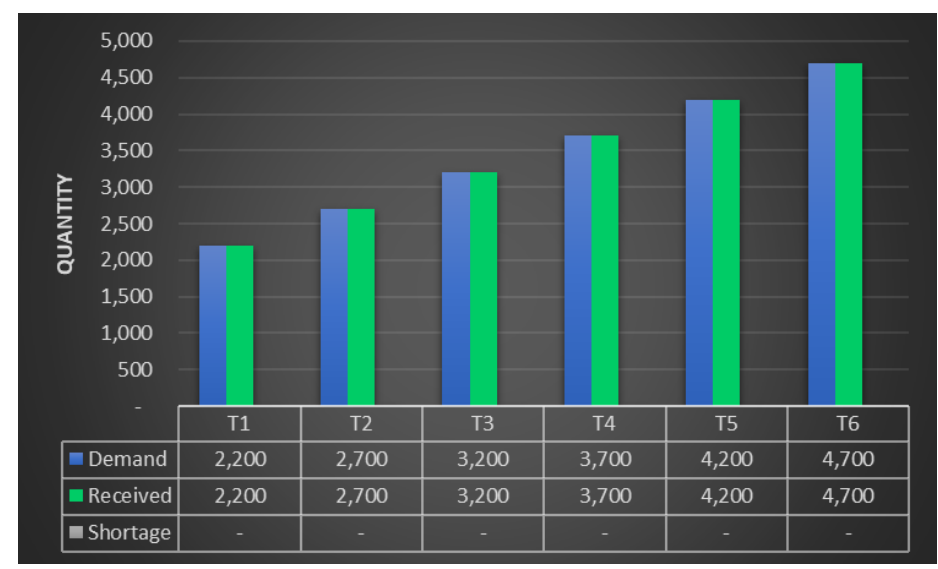

Fig 4. The first retailer's demand, received, and shortage of the first product

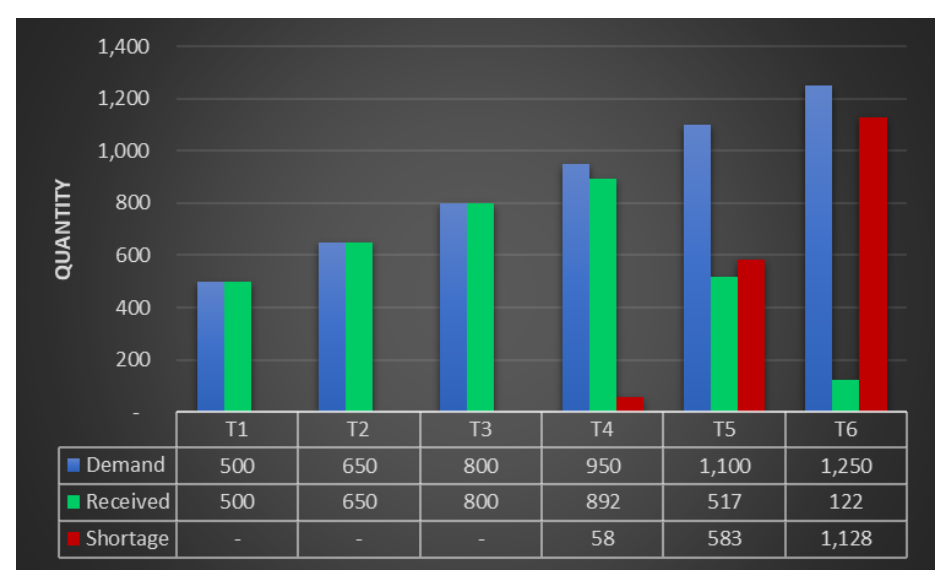

Fig 5. The first retailer's demand, received, and shortage of the Second product.

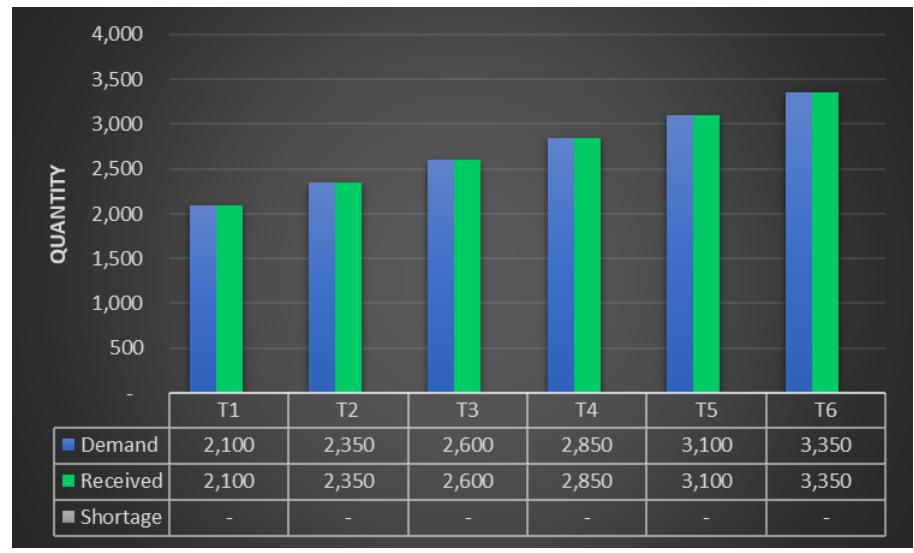

Fig 6. The second retailer's demand, received, and shortage of the first product 


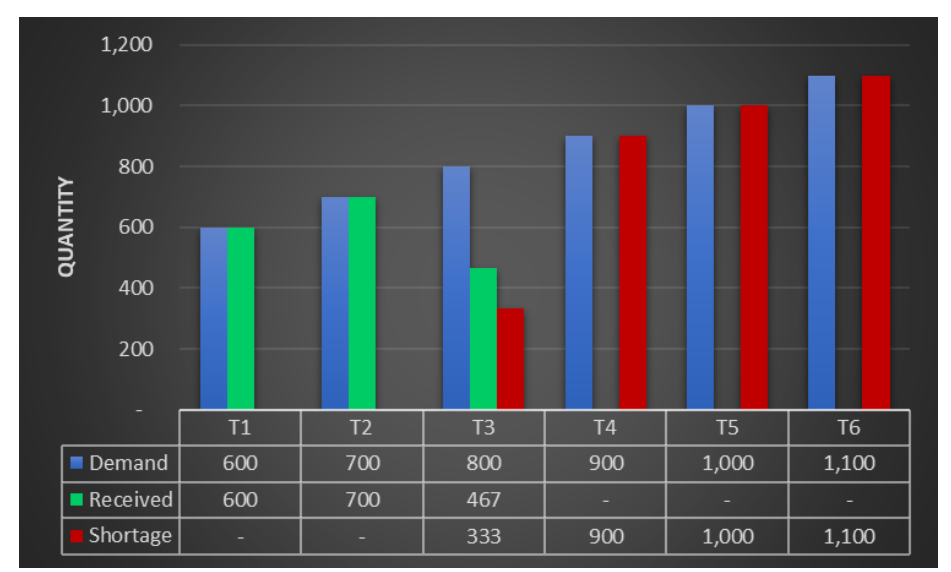

Fig 7. The second retailer's demand, received, and shortage of the second product.

Table 3. Balancing of the supplied material and the received products.

\begin{tabular}{|c|c|c|c|c|c|c|c|}
\hline & Period & $\mathrm{T} 1$ & $\mathrm{~T} 2$ & T3 & $\mathrm{T} 4$ & T5 & T6 \\
\hline \multirow{7}{*}{ Supplied Item 1} & Qsit11 & 788 & 1,300 & 1,533 & 1,533 & 1,533 & 1,533 \\
\hline & Qsit21 & 1,800 & 1,800 & 1,800 & 1,800 & 1,800 & 1,800 \\
\hline & Nsit11 & 7,880 & 13,000 & 15,333 & 15,333 & 15,333 & 15,333 \\
\hline & Nsit21 & 18,000 & 18,000 & 18,000 & 18,000 & 18,000 & 18,000 \\
\hline & I1 in II & 120 & & & & & \\
\hline & \multirow{2}{*}{ SUM } & 26,000 & 31,000 & 33,333 & 33,333 & 33,333 & 33,333 \\
\hline & & 190,333 & & & & & \\
\hline \multirow{5}{*}{ Received Item 1} & $\mathrm{I} 1$ in $\mathrm{P} 1$ & 17,120 & 20,200 & 23,200 & 26,200 & 29,200 & 32,280 \\
\hline & $\mathrm{I} 1$ in $\mathrm{P} 2$ & 8,720 & 10,800 & 10,133 & 7,133 & 4,133 & 1,053 \\
\hline & $\mathrm{I} 1$ in FI & - & - & - & - & - & 160 \\
\hline & \multirow{2}{*}{ SUM } & 25,840 & 31,000 & 33,333 & 33,333 & 33,333 & 33,493 \\
\hline & & 190,333 & & & & & \\
\hline \multirow{7}{*}{ Supplied Item 2} & Qsit12 & - & - & - & - & - & - \\
\hline & Qsit22 & 2,588 & 3,100 & 3,333 & 3,333 & 3,333 & 3,333 \\
\hline & Nsit12 & - & - & - & - & - & - \\
\hline & Nsit22 & 12,940 & 15,500 & 16,667 & 16,667 & 16,667 & 16,667 \\
\hline & I2 in II & 60 & & & & & \\
\hline & \multirow{2}{*}{ SUM } & 13,000 & 15,500 & 16,667 & 16,667 & 16,667 & 16,667 \\
\hline & & 95,167 & & & & & \\
\hline \multirow{5}{*}{ Received Item 2} & $\mathrm{I} 2$ in $\mathrm{P} 1$ & 8,560 & 10,100 & 11,600 & 13,100 & 14,600 & 16,140 \\
\hline & $\mathrm{I} 2$ in $\mathrm{P} 2$ & 4,360 & 5,400 & 5,067 & 3,567 & 2,067 & 527 \\
\hline & $\mathrm{I} 2$ in FI & & & & & & 80 \\
\hline & \multirow{2}{*}{ SUM } & 12,920 & 15,500 & 16,667 & 16,667 & 16,667 & 16,747 \\
\hline & & 95,167 & & & & & \\
\hline
\end{tabular}


Table 4. The assumed parameters

\begin{tabular}{|c|c|c|c|c|c|c|c|}
\hline No. & Input parameter & Value & Unit & No. & Input parameter & Value & Unit \\
\hline 1 & Ppct & 100,100 & \$/Unit & 8 & REQip & $1,10,1,10$ & Kg./unit \\
\hline 2 & CAPsit & 20,000 & Hrs & 9 & SCPUp & 5,10 & $\$ /$ period \\
\hline 3 & CAPHft & 20,000 & $\mathrm{Kg}$ & 10 & $\mathrm{HC}$ & 2,4 & $\$ / \mathrm{kg}$. period \\
\hline 4 & CAPMft & 20,000 & Hrs & 11 & Bsi & 10 & Unit \\
\hline 5 & CAPFSft & 10,000 & $\mathrm{Kg}$ & 12 & Ts, Tf & $0.005,0.001$ & $\$$ \\
\hline 6 & MATCit & 1,2 & $\$ / \mathrm{kg}$ & 13 & $\mathrm{FC}$ & 50,000 & $\$$ \\
\hline 7 & Dsf, Dfc & 50 & $\mathrm{Km}$ & & & & \\
\hline
\end{tabular}

revenue increases as the demand increase till the demand of almost 1500 item/period, where the capacity of the factory has been consumed as observed from the OSL graph. Thereafter, the increasing rate of revenue has been decreased due to the shortage in satisfying the demand till a demand of 5000 units per period. However, the total revenue remains constant because of the stability in production. Furthermore, the total cost increases as long as the demand increases even after reaching the maximum capacity, the rate increased significantly due to the shortage cost. Accordingly, the profit increases as a result of a rise in profit and decreases on reaching the limiting capacity.

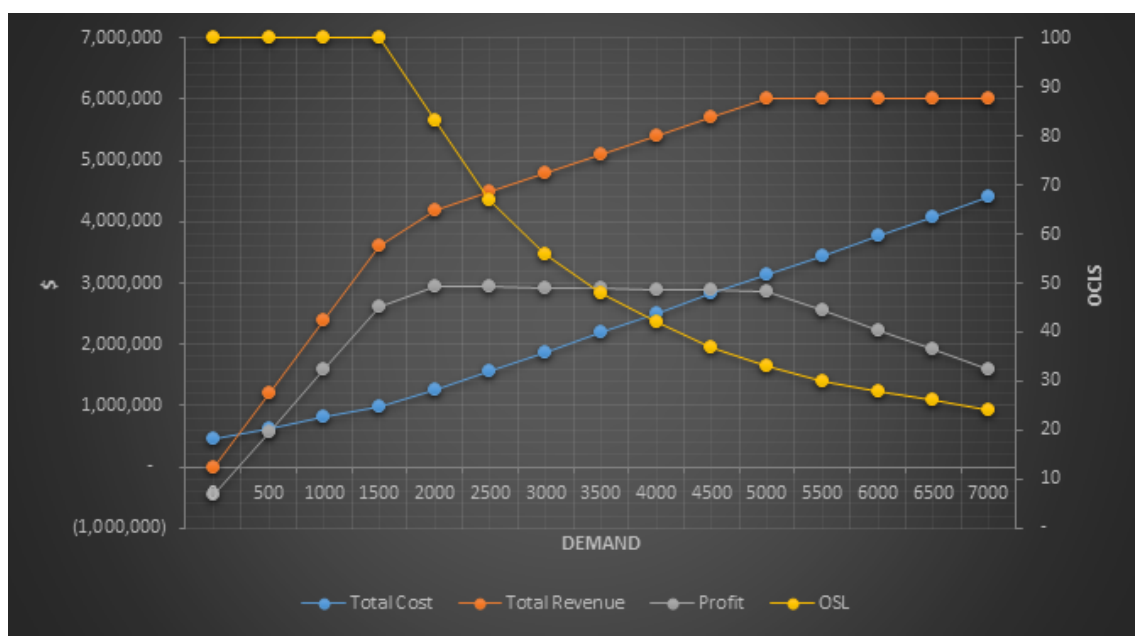

Fig 8. Effect of demand of the revenue, cost, profit, and OSL

\section{Conclusion}

The developed multi-item, multi-product, and multi-period mathematical model has successfully optimized the supply, production, distribution, and inventory planning for a multi-echelon supply chain of two suppliers, one factory, and two retailers to maximize the profit.

The efficiency of this model has been verified by solving and analyzing the results of a comprehensive example. Also, the effect of demand on the total revenue, cost, profit, and OSL have been studied and analyzed.

\section{Limitations:}

1. The model is limited to non-perishable products and materials.

2. For larger problems, it is recommended that software like GAMS or Xpress be used instead of Evolver.

\section{Future scope: It is recommended that the model be developed in order to;}

1. Tackle the robust demand problems

2. Optimize more than one objective like maximizing the overall service level and minimizing the total cost. 
3. Considering the time value of money and the interest rate by optimizing the NPV.

4. Study the same problem under disruptions and modularity.

\section{References}

1) Chen CT, Huang SF. Order-fulfillment ability analysis in the supply-chain system with fuzzy operation times. International Journal of Production Economics. 2006;101(1):185-193. Available from: https://dx.doi.org/10.1016/j.ijpe.2005.05.003.

2) Mentzer JT, DeWitt W, Keebler JS, Min S, Nix NW, Smith CD, et al. Defining supply chain management. Journal of Business Logistics. 2001;22(2):1-25. Available from: https://dx.doi.org/10.1002/j.2158-1592.2001.tb00001.x.

3) Towill DR. Time compression and supply chain management - a guided tour. Supply Chain Management: An International Journal. 1996;1(1):15-27. Available from: https://dx.doi.org/10.1108/13598549610799040.

4) Alashhab MS. Developing a robust green supply chain planning optimization model considering potential risks. International Journal of GEOMATE. 2020;19(73):208-223. Available from: https://dx.doi.org/10.21660/2020.73.52896.

5) Wang F, Lai X, Shi N. A multi-objective optimization for green supply chain network design. Decision Support Systems. 2011;51(2):262-269. Available from: https://dx.doi.org/10.1016/j.dss.2010.11.020.

6) El-Sayed M, Afia N, El-Kharbotly A. A stochastic model for forward-reverse logistics network design under risk. Computers \& Industrial Engineering. 2010;58(3):423-431. Available from: https://dx.doi.org/10.1016/j.cie.2008.09.040.

7) Al-Ashhab MS, Nabil OM, Afia NH. Perishable products supply chain network design with sustainability. Indian Journal of Science and Technology. 2021;14(9):787-800. Available from: https://dx.doi.org/10.17485/ijst/v14i9.24.

8) Dwivedi A, Jha A, Prajapati D, Sreenu N, Pratap S. Meta-heuristic algorithms for solving the sustainable agro-food grain supply chain network design problem. Modern Supply Chain Research and Applications. 2020;2(3):161-177. Available from: https://dx.doi.org/10.1108/mscra-04-2020-0007.

9) Mogale DG, Kumar SK, Tiwari MK. Green food supply chain design considering risk and post-harvest losses: a case study. Annals of Operations Research. 2020;295(1):257-284. Available from: https://dx.doi.org/10.1007/s10479-020-03664-y.

10) Chan FTS, Wang ZX, Goswami A, Singhania A, Tiwari MK. Multi-objective particle swarm optimisation based integrated production inventory routing planning for efficient perishable food logistics operations. International Journal of Production Research. 2020;58(17):5155-5174. Available from: https://dx.doi.org/10.1080/00207543.2019.1701209.

11) Wang C. Research on Optimal Design of Short-Life Cycle Product Logistics Supply Chain Based on Multicriteria Decision Model. Security and Communication Networks. 2021;2021:1-12. Available from: https://doi.org/10.1155/2021/5564831.

12) Al-Ashhab MS, Attia T, Munshi SM. Multi-Objective Production Planning Using Lexicographic Procedure. American Journal of Operations Research. 2017;07(03):174-186. Available from: https://dx.doi.org/10.4236/ajor.2017.73012.

13) Al-Ashhab MS, Afia N, Shihata LA. Objective Effect on the Performance of a Multi- Period Multi-Product Production Planning Optimization Model. International Journal of Mechanical \& Mechatronics Engineering IJMME-IJENS IJENS I J E N S. 2016;16(03). 